\title{
Unusual presentation of necrotic nodular scleritis
}

\author{
W. N. DUGMORE \\ Victoria Hospital, Burnley, Lancashire
}

Holthouse (1893) described painful ulceration in an apparent nodule of episcleritis, with resulting perforation of the globe (Duke-Elder, 1938). According to Francois (195I), the case reported was not one of episcleritis but the represented first description of necrotic nodular scleritis. Watson (1966) states that the sclera is rarely involved in episcleritis.

All forms of necrotizing scleritis are grouped under the term necrogranulomatous scleritis (Sevel, 1965). Pain is an inconstant feature, being absent in scleromalacia perforans and present in rheumatic nodule (Ashton and Hobbs, 1952) and necrotic nodular scleritis (Franceshcetti and Bischler, 1950). The following case report records painless scleral necrosis, initially presenting as a nodule of episcleritis, and its subsequent treatment by surgery.

\section{Case report}

A man aged 44 years attended the out-patients department at the Victoria Hospital, Burnley, on March 9, I971, complaining of deterioration of vision in the right eye for 3 months. He volunteered the information that a painless swelling on the temporal side of the limbus, which was increasing in size, had been present for 12 months. Since December, 1950, repeated attacks of iridocyclitis had occurred in the right eye. Arthralgia in both knee joints was diagnosed in 1960 when a latexfixation test was positive.

\section{EXAMINATION}

The visual acuity was $3 / 60$ in the right eye and 6/6 in the left. At 7 o'clock in the right eye there was a bright red swelling about $4 \mathrm{~mm}$. in diameter and $2 \mathrm{~mm}$. from the limbus. Corneal sensation was present. The slit lamp showed, superficial to the swelling, slight dilatation of the vessels in the subconjunctival plexus and gross dilatation of the anastomotic superficial episcleral plexus vessels. Seclusio pupillae and cataract were observed but no flare, cells, or keratic precipitates in the anterior chamber.

\section{TREATMENT}

Prednisolone drops 8-hrly.

PROGRESS

On March 19, the swelling was a smooth, trilobed, cream-coloured excrescence, about $5 \mathrm{~mm}$. in diameter encroaching on the limbus (Fig. I, overleaf).

In-patient treatment was advised but the patient refused to enter hospital until April i4. Prednisolone drops were stopped and chloramphenicol ointment was prescribed.

\section{OPERATION}

On April 14 the conjunctiva was incised; arising from the sclera was a tumour, which, when punctured, discharged a milky fluid. After excision of the swelling the scleral gap was covered by conjunctiva. 
( I)

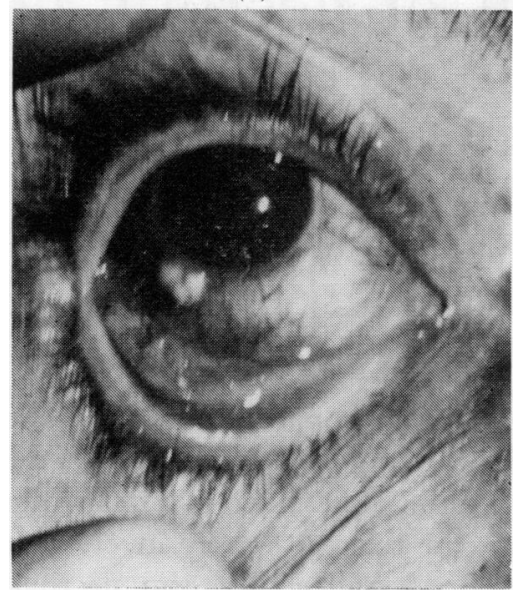

(2)

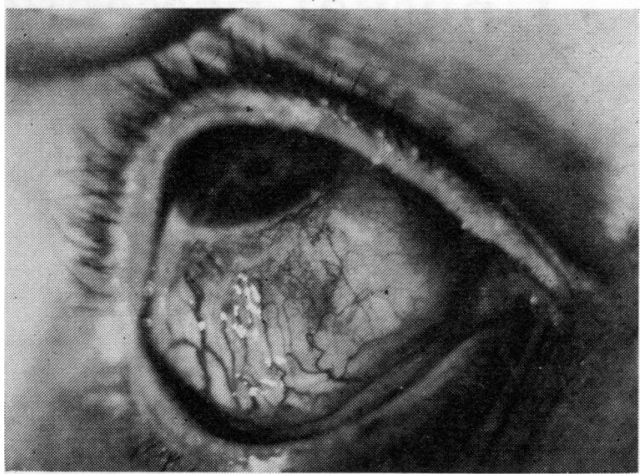

FIG. 2 Appearance on May 14, I97 I

FIG. I Appearance on March 19, I97 I

Fluid. Amorphous necrotic debris. No polymorphs or organisms seen. Cultures sterile. Granulation tissue found on section.

RESULT

On May I4, the sclera had completely healed (Fig. 2).

\section{Discussion}

The distinction between episcleritis and scleritis may be difficult. The initial lesion was diagnosed as a nodule of episcleral inflammation. This diagnosis was based on the characteristic appearance of the vascular pattern of the anterior segment of the eye (Watson, 1966). Topical steriod treatment failed to suppress the inflammatory reaction and to prevent necrosis. Considering the chronicity of the lesion, and the juxtaposition in time of local steroid treatment to necrosis, it is surmised that the ncerosis may have been precipitated by the use of prednisolone drops. Excision of the necrotic area may appear to be the best form of treatment. New collagen material has been rapidly laid down with no clinical evidence of scleral thinning or subsequent likelihood of scleral ectasia and staphyloma formation.

Secondary scleritis may complicate uveitis (Duke-Elder, 1938). In this case these are considered to have occurred coincidentally, but with a possible single background, i.e. polyarthritis.

The absence of severe pain is puzzling. Possible explanations include toxic involvement of the long and short ciliary nerves by episodes of iridocyclitis causing local damage to the nerves; rapid local involvement of the ciliary fibres in the necrotic reaction; individual raised pain threshold or stoicism.

The differential diagnosis in this case must include scleromalacia perforans which can appear as raised, multiple yellow nodules. It was excluded because the patient was under $5^{\circ}$ years old, there was no deforming rheumatic polyarthritis, and the characteristic ocular features were absent (François, 195I). 


\section{Summary}

A case of painless necrotic nodular scleritis, preceded by episcleritis, is described. Surgical treatment was successful. Differential diagnosis and absence of pain are discussed.

I wish to thank Dr. Behr and Mr. Taylor for the photographs and Mrs. M. J. Hudson for her help in the preparation of this paper.

\section{References}

Ashton, N., and hoBBs, н. Е. (1952) Brit. 7. Ophthal., 36, 373

DUKE-ELDER, s. (1938) “Text-book of Ophthalmology", vol. 2, pp. 2052-2065. Kimpton, London FRANçOIS, J. (195I) Trans. ophthal. Soc. U.K., 71, 6I

fRANCESCHETti, A., and Bischler, v. (1950) Ann. Oculist. (Paris), 183, 737

HOlthouse, E. H. (1893) Roy. Lond. ophthal. Hosp. Rep., 13, 415

SEVEL, D. (1965) Trans. ophthal. Soc. U.K., 85, 357

WATson, P. G. (I 966$)$ Ibid., 86, I 5 I 